\title{
Cholesterol metabolism and homeostasis in the brain
}

\author{
Juan Zhang, Qiang Liu ${ }^{\bowtie}$ \\ Chinese Academy of Sciences Key Laboratory of Brain Function and Disease, and School of Life Sciences, University of \\ Science and Technology of China, Hefei 230026, China \\ $\bowtie$ Correspondence: liuq2012@ustc.edu.cn (Q. Liu) \\ Received November 25, 2014 Accepted December 19, 2014
}

\begin{abstract}
Cholesterol is an essential component for neuronal physiology not only during development stage but also in the adult life. Cholesterol metabolism in brain is independent from that in peripheral tissues due to bloodbrain barrier. The content of cholesterol in brain must be accurately maintained in order to keep brain function well. Defects in brain cholesterol metabolism has been shown to be implicated in neurodegenerative diseases, such as Alzheimer's disease (AD), Huntington's disease (HD), Parkinson's disease (PD), and some cognitive deficits typical of the old age. The brain contains large amount of cholesterol, but the cholesterol metabolism and its complex homeostasis regulation are currently poorly understood. This review will seek to integrate current knowledge about the brain cholesterol metabolism with molecular mechanisms.
\end{abstract}

\section{KEYWORDS cholesterol metabolism, homeostasis, apoE}

\section{INTRODUCTION}

Brain lipids consist of glycerophospholipids, sphingolipids, and cholesterol, they are in roughly equimolar proportions (Korade and Kenworthy, 2008). In this review, we focus on the most well studied lipid-cholesterol. Brain is the most cholesterol-rich organ, it contains about $20 \%$ of the whole body's cholesterol (Björkhem et al., 2004). Unesterified cholesterol is the major sterol in the adult brain, and small amounts of desmosterol and cholesteryl ester are also present. The majority (about $70 \%-80 \%$ ) of cholesterol in the adult brain is in myelin sheaths formed by oligodendrocytes to insulate axons, the rest is made up by plasma membranes of astrocytes and neurons to maintain their morphology and synaptic transmission (Dietschy and Turley, 2004).

Neurons need to build up a large amount of membrane surface of their axons, dendrites and synapses, including postsynaptic spines and presynaptic vesicles, where significantly high cholesterol content was detected (Goritz et al., 2005; Pfenninger, 2009; Takamori et al., 2006). Cholesterol is not only an essential structural component for cellular membrane and myelin, a precursor of steroid hormones and bile acid synthesis, but also a required component for synapse and dendrite formation (Goritz et al., 2005; Fester et al., 2009), axonal guidance (De Chaves et al., 1997). Cholesterol can also influence cell function through its biologically active oxidized product-oxysterol (Janowski et al., 1999; Björkhem, 2006; Radhakrishnan et al., 2007). Cholesterol is essential for neuronal physiology, both during development and in the adult stage. Cholesterol depletion in neurons impairs synaptic vesicle exocytosis, neuronal activity and neurotransmission, leads to dendritic spine and synapse degeneration (Linetti et al., 2010; Liu et al., 2010; Liu et al., 2007). Defects in cholesterol metabolism lead to structural and functional central nervous system (CNS) diseases such as Niemann-Pick $C$ disease, Huntington's disease, Alzheimer's disease and Parkinson's disease (Madra and Sturley, 2010; Block et al., 2010; Di Paolo and Kim, 2011; Wang et al., 2011).

\section{CHOLESTEROL SYNTHESIS AND TURNOVER IN THE BRAIN}

The amount of sterol in brain ranges about $15-20 \mathrm{mg}$ per $\mathrm{g}$ in many species, among them most of the sterol is unesterified cholesterol (Dietschy and Turley, 2004). The steady concentration remains essentially constant under normal physical conditions. However, a fraction of the pool is constantly 


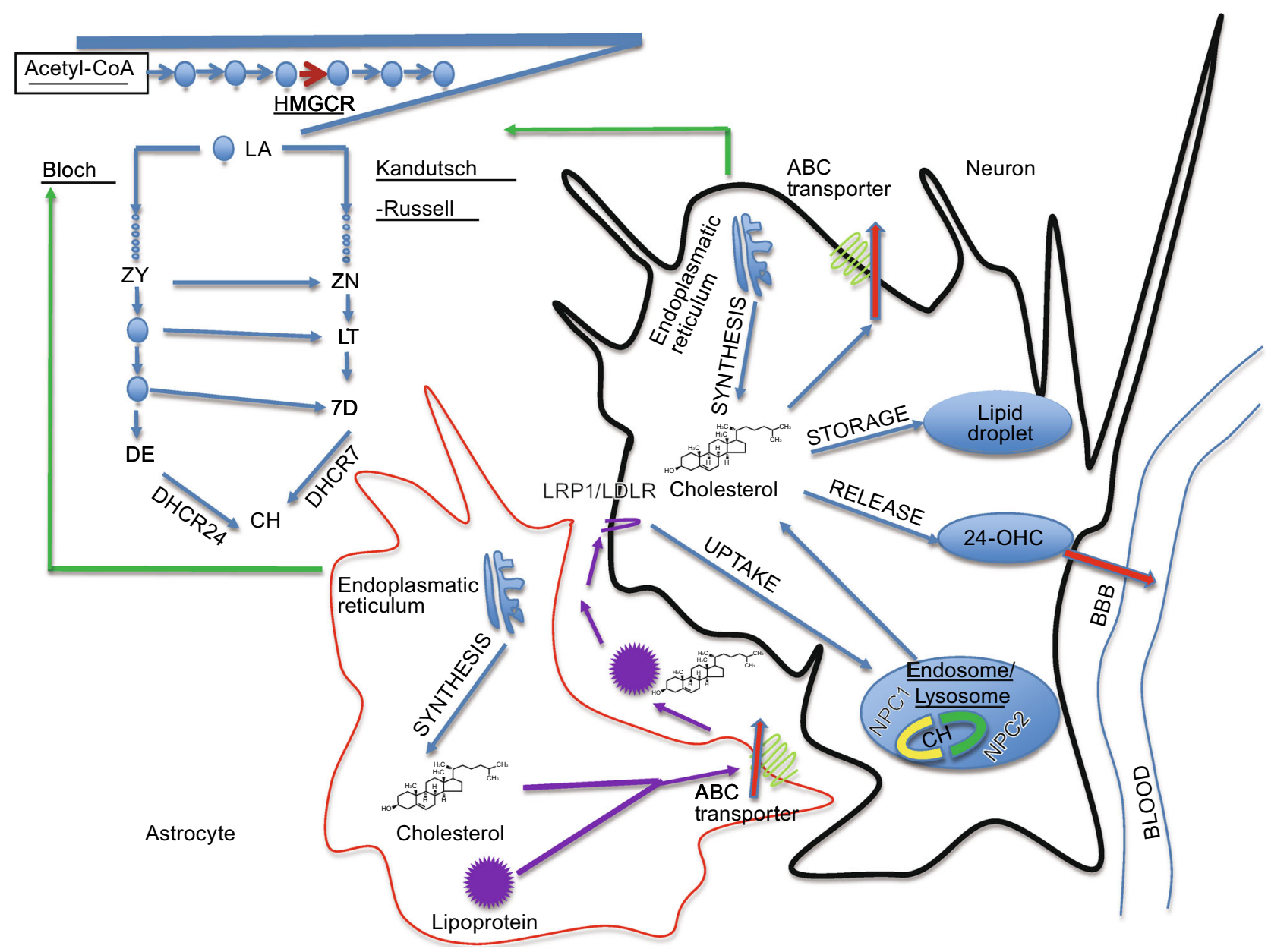

Figure 1. Cholesterol synthesis and metabolism in the brain. Cholesterol in neurons is primarily biosynthesized through Kandutsch-Russell pathway, whereas in astrocytes through Bloch pathway. Adult neurons essentially rely on astrocyte for cholesterol providing. Cholesterol uptake is via LRP1/LDLR receptors as apoE-containing cholesterol form. It is then converted to free cholesterol in endosome/lysosome in assistance of NPC1 and NPC2. Excess of cholesterol is prevented by intracellular esterification and storage in lipid droplets, or released as a complex with apolipoprotein-containing lipoprotein via ATP-binding cassette transporter, or converting to oxysterols then passing through BBB.

replaced. Mechanisms must be in place to constantly excrete or degrade cholesterol, at the same time, to constantly supply an equivalent amount of new sterol to the cell plasma membranes. These two processes also must be so tightly regulated that the steady-state concentration of cholesterol in the brain remains essentially constant.

\section{Cholesterol synthesis in the brain}

Brain cholesterol in adult mice is primarily supplied by de novo syntheses due to the prevention of lipoproteins uptake from the circulation by blood brain barrier (BBB) (Jeske and Dietschy, 1980). Cholesterol's metabolism in brain is separated from the rest of the body in the presence of intact blood brain barrier. Cellular cholesterol synthesis is a complex and resource-intense process. It starts with the conversion of acetyl-CoA to 3-hydroxy-3-methylglutaryl-CoA by
HMG-CoA, 3-hydroxy-3-methylglutaryl-CoA is then converted to mevalonate by HMG-CoA reductase. HMG-CoA is considered the rate-limiting and irreversible step in cholesterol synthesis. A series of enzymatic reactions occur converting mevalonate into 3-isopenenyl pyrophosphate, farnesyl pyrophosphate, squalene, lanosterol, and another 19-step process to final product-cholesterol (Berg, 2002). The majority of brain cholesterol accumulates between the perinatal period and adolescence when neurons are encircled by myelin. This de novo synthesis is adequate accounting for the cholesterol accumulation rate during early development, when myelin production by oligodendrocytes takes place. Moreover, the synthesis rate also closely correlates with the ultimate cholesterol level in different brain regions (Quan et al., 2003). Similar finding has been reported in rat (Jurevics and Morell, 1995; Jurevics et al., 1997). The highest cholesterol synthesis rate in human and 
rodents takes place when the peak of myelination process occurs, the myelination process is delayed when cholesterol synthesis is deficient (Saher et al., 2005). After myelination, the metabolism of cholesterol in the adult brain maintains at a very low turnover and minimal losses (Morell and Jurevics, 1996). The half-life of cholesterol in the adult brain is between 6 months and 5 years (Andersson et al., 1990; Björkhem et al., 2006), in contrast, the half-life of plasma cholesterol is only a few days (Dietschy and Turley, 2004).

De novo cholesterol synthesis takes place primarily in the endoplasmic reticulum (ER), newly synthesized cholesterol is transferred from ER to the plasma membrane (PM) rapidly (DeGrella and Simoni, 1982). The synthesis process is ATP dependent but is independent of passage through the Golgi apparatus (Kaplan and Simoni, 1985; Heino et al., 2000). The redistribution of cholesterol in different subcellular compartment is maintained by a combination of vesiclemediated inter-organelle transport and protein-mediated monomeric transfer through the aqueous cytoplasm. Since cholesterol is water insoluble, quantitatively very little unbound cholesterol is detected in cytosol, most of the cholesterol exists as protein binding form such as apoE containing cholesterol particle in cytosol. While a role in cholesterol transport has been proposed for these proteins, whether they have additional functions other than sole transporters still remain unknown.

\section{Cholesterol synthesis in neurons and astrocytes}

Different profiles of post-squalene precursors were observed in neurons in comparison to astrocytes (Fig. 1). Neurons contain mainly sterols of Kandutsch-Russel pathway, including precursors lanosterol (LA), 7-dehydrocholesterol (7D), and lathosterol (LT) whereas astrocytes contain precursors of the Bloch pathway, such as desmosterol (DE) (Nieweg et al., 2009). In adult neurons, radioactive label was mainly found in lanosterol, whereas in glial cells it accumulated predominantly in cholesterol (Nieweg et al., 2009). A very low level of lanosterol-converting enzymes-24-dehudrocholesterol reductase (DHCR24) and lanosterol 14-alpha demethulase (CYP51) were detected in adult neurons, indicating that neurons have difficulty converting lanosterol efficiently. It was detected that adult neurons have a lower rate of sterol synthesis in comparison to glial cells. All the evidences demonstrate that adult neurons have a lower capacity to compensate for a cholesterol deficit by de novo synthesis in comparison to astrocytes. However, in situ hybridization data from the Allen Mouse Brain Atlas suggest that transcript level of many cholesterol synthesis enzymes are higher in neurons compared to these in astrocytes (Valdez et al., 2010), although higher transcript level doesn't necessarily mean the actual protein level and enzymatic activity have the same pattern. Compartmented culture studies showed that in neurons, cholesterol synthesis is restricted to neuronal somata and does not occur in axons, but phospholipids formation takes place in both compartments, newly synthesized cholesterol in neurons is transported from soma to axon (Vance et al., 1994).

\section{CHOLESTEROL TURNOVER}

When cholesterol synthesis rate exceeds its acquisition rate in the brain, that is when the net excretion of cholesterol occurs. Cholesterol overload often happens to adult neurons, because they primarily rely on exogenous cholesterol, whereas astrocytes produce cholesterol in excess to satisfy adult neurons' functional needs. Several pathways for cholesterol turnover have been identified so far (Fig. 1).

\section{Cholesterol storage}

About $1 \%$ of the total cholesterol content exists as esterified form (Bryleva et al., 2010; Liu et al., 2009), it is also called lipid droplets. This is considered as a way to store surplus cholesterol intracellularly. Cholesterol is esterified by acylcoenzyme A: cholesterol acyltransferase 1 (ACAT1/SOAT1). This process takes place primarily in the endoplasmic reticulum. The rate of cholesterol movement from the plasma membrane to the endoplasmic reticulum is higher in cells with increased cholesterol levels, leading to an enhancement of the storage process in cells with excess unesterified cholesterol (Wustner et al., 2005). Genetic reduction of ACAT1/SOAT1 in mice decreased the concentration of cholesterol esters in the brain by $86 \%$ (Hutter-Paier et al., 2004). A genetic association study in humans also showed that a variant of ACAT1/SOAT1 gene is associated with lower levels of cholesterol in the CSF (Wollmer et al., 2003a). The ACAT1/SOAT1 enzyme is more active in neurons than in glial cells (Sakashita et al., 2000). ACAT1/SOAT1 becomes active in astrocytes under conditions like lacking apoE and when exogenous cholesterol is overloaded (Karten et al., 2006).

\section{Conversion to oxysterol}

This is the major excretion way in the brain. The hydroxylation of cholesterol to 24-hydroxycholesterol (24-OHC) is catalyzed by cholesterol 24-hydroxylase (encoded by CYP46A1, which is a member of the cytochrome p450 family). Unlike non-oxydized cholesterol, oxysterols such as 24-hydroxycholesterol can cross lipophilic membranes such as the brain blood barrier (BBB) at a much faster rate than cholesterol itself (Lange et al., 1995; Meaney et al., 2002). However, the expression of this enzyme is restricted to certain types of neurons in the brain, such as pyramidal cells of the cortex and Purkinje cells of the cerebellum (Lund et al., 2003; 1999; Lütjohann et al., 1996), suggesting that these cells are particularly sensitive to excess of cholesterol. Immunocytochemical staining of cultured neurons showed that CYP46A1 is located primarily in somata and dendrites of neurons, but not in axons or presynaptic terminals (Ramirez et al., 2008). There is little expression of cholesterol 24-hydroxylase in glial cells in the brain (Ramirez et al., 2008). 
This indicates that the major cholesterol turnover takes place in neurons, not in astrocytes.

Disruption of the murine cholesterol 24-hydroxylase gene reduced the rate of cholesterol synthesis in the brain by $40 \%$, whereas the brain content of cholesterol was unaltered (Lund et al., 2003), this is possibly due to the concomitant reduction in the cholesterol mevalonate pathway. All the evidences indicate that 24-hydroxylase pathway only accounts for a portion of cholesterol metabolism. Cholesterol synthesis is decreased in hippocampus of aging brain, the 24S-hydroxycholesterol level is slightly decreased as well. This could explain why the absolute cholesterol content remains at the same level (Thelen et al., 2006).

\section{Secretion via $A B C$ transporter}

Neurons express $A B C$ transporters, namely $A B C A 1$, ABCG1, and ABCG4 (Kim et al., 2008), to mediate cellular sterol efflux at the plasma membrane. ABCA1 is expressed by neurons in embryonic and adult rodents (Wellington et al., 2002; Koldamova et al., 2003), the expression level in neurons is much higher than in astrocytes (Tarr and Edwards, 2008). This pathway is CYP46A1 independent for cholesterol elimination from neurons. Cholesterol is directly released onto APOA1-containing lipoproteins that is present in CSF (Roheim et al., 1979; Pitas et al., 1987a; Koch et al., 2001), then these lipoproteins could be removed from the brain through LRP1 or scavenger receptor class B1, both of these two receptors are expressed in brain capillary endothelial cells (Panzenboeck et al., 2002; Gosselet et al., 2009). Down-regulation of ABCA1 levels in cultured neurons reduced the efflux of cholesterol onto externally supplied apoE, whereas, increased ABCA1 levels enhanced the lipid release (Minagawa et al., 2009). Taken together, neurons may handle excess cholesterol by esterification and subsequent intracellular storage, by direct excretion via $A B C$ transporters and by conversion to $24-\mathrm{OHC}$.

\section{CHOLESTEROL HOMEOSTASIS IN THE BRAIN}

A sufficient availability of cholesterol is necessary for normal neuronal function and morphology, neuronal cells' function is impaired not only due to lack but also surplus of cholesterol (Ko et al., 2005; Pooler et al., 2006). Defects of cholesterol homeostasis in the adult brain are linked to neurodegenerative diseases like Niemann-Pick type $\mathrm{C}$ disease or Alzheimer's disease (Madra and Sturley, 2010; Block et al., 2010; Di Paolo and Kim, 2011; Wang et al., 2011). It is well established that neuronal cells regulate their cholesterol content by an exquisite feedback mechanism that balances biosynthesis, import, and excretion. Cells sense their level of cholesterol by membrane-bound transcription factors known as sterol regulatory element-binding proteins (SREBPs), which regulates the transcription of genes encoding enzymes of cholesterol and fatty acid biosynthesis as well as lipoprotein receptors (Brown and Goldstein, 1999) to either increase cholesterol synthesis and uptake in sterol-depleted cells or decrease cholesterol-synthesizing enzymes when sterols are overloaded in cells (DeBose-Boyd et al., 1999; Nohturfft et al., 2000). When cholesterol reaches the maximum required level, 24-hydroxylase catalyzes cholesterol to 24-hydroxycholesterol (24-OHC), that can be eliminated in the presence of HDL as a lipid acceptor and protects neurons from the toxic effect of 24-OHC accumulation (Matsuda et al., 2013). 24-OHC, beside being a metabolite for elimination of cholesterol, it also serves as an activator of nuclear transcription factors, for example, liver $X$ receptors $\alpha$ and $\beta$, which increase the expression of cholesterol transport genes (Rebeck, 2004; Tall, 2008) including ABCA1 in both neuron and glia cell (Fukumoto et al., 2002), apoE in astrocyte (Liang et al., 2004; Pfrieger and Ungerer, 2011), consequently cholesterol efflux is increased. ABCA1 is one of the major mediators for cholesterol homeostasis. During the early period of development, when the majority of growth and myelination takes place, the net cholesterol flux increase rapidly. After myelination, cholesterol synthesis continues at a very low level in the CNS. Neurons do not efficiently synthesize cholesterol after myelination completes and mainly rely on external source of cholesterol (Quan et al., 2003). Conditional ablation of cholesterol synthesis in mice neurons leads to significant transfer and uptake of glia-derived cholesterol by neurons. However, under certain condition, for example when brain-derived neurotropic factor (BDNF) is in present, the endogenous synthesis of cholesterol in neuron is partially restored (Numakawa et al., 2010). Cholesterol synthesis ablation in neuronal precursor cell during embryonic development leads reduced brain size and perinatal lethality and newly generated neurons (Saito et al., 2009). All these evidences indicate that cholesterol synthesis in neurons is essential at early development stage. On the other hand, mice lacking cellular cholesterol synthesis in adult neurons were phenotypically indistinguishable from controls, furthermore, no obivious signs of neurodegeneration or inflammation were observed (Fünfschilling et al., 2007). This indicates that cholesterol synthesis is not essential in adult neurons. Lipoprotein related protein (LRP) level remains the same in this mouse model too, this also supports that adult neurons already express sufficient LRP to import cholesterol as apoE-containing lipoprotein particles. All the evidences advocate that some adult neurons do not require cell autonomous cholesterol synthesis, which is very likely to rely on oligodendrocytes and astrocytes for cholesterol providing, especially, astrocytes, as they express apoE in vivo and neuronal cell can import cholesterol through receptor-mediated endocytosis of lipoproteins such as apoE binding form. The apoE-cholesterol particle is processed to free cholesterol in lysosome after being endocytosised (Ikonen, 2008; Fagan and Holtzman, 2000) and then transported to membrane. The cholesterol transport between cells is influenced by the fluidity of cell membranes and the distribution of microdomains such as lipid rafts. When membrane fluidity elevated (Xu et al., 2001), the intermolecular packing of 
phospholipid fatty acyl chains decreases (Ollila et al., 2007), the altered membrane composition leads to functional change.

It has been believed for a long time that glia only passively support neurons, but evidence shows that glia is actively involved in assisting neuronal functions like synaptogenesis (Pfrieger and Barres, 1997; Ullian, 2001). Cholesterol in apoE particles secreted by astrocytes increases the induced synaptic responses substantially in neuronal culture by increasing presynaptic function and dendrite differentiation (Christopherson et al., 2005; Mauch et al., 2001). Neuronal culture in presence of astrocytes showed about 10 fold more excitatory synapse activity and 5-7 fold increase of synapse numbers. Thrombospondins (TSPs), a family of extracellular matrix proteins, has found to increase synapse number in neuronal culture. Removal of TSPs from astrocyte-conditional medium diminishes the synaptogenic activity of the medium. All those indicated that TSPs are necessary and sufficient synaptogenic factor for synapse formation. Besides this, astrocytes also produce messenger RNAs that encode several synaptic adhesion proteins, including neurexins, neuroligins, and cadherins (Cahoy et al., 2008), that are known to be important for synapse formation and are believed function in neurons only (Fox and Umemori, 2006).

\section{MAJOR REGULATORS IN BRAIN CHOLESTEROL METABOLISM}

\section{Apolipoproteins (apoE) in the brain}

Apolipoprotein $\mathrm{E}(\mathrm{ApoE})$, a $39-\mathrm{kDa}$ protein, is a major apolipoprotein in the CNS, which is highly expressed in brain, such that the brain is the organ with the second highest apoE expression after liver (Linton et al., 1991). ApoE-containing lipoproteins secreted by glial cells bind to lipoprotein receptors, and being taken up into neurons. The major function of apoE is participating in cholesterol homeostasis. Astrocytes are the major source of apoE followed by oligodendrycytes, microglia, and ependymal layer cells (Mahley et al., 2006). Neurons may express apoE under certain condition such as excitotoxic injury (Xu et al., 1999). When nerve injury happens in central nervous systems, the synthesis of apoE by glial cells increased up to 150 fold (Ignatius et al., 1986; Snipes et al., 1986; Boyles et al., 1990). There is a dynamic exchange of apoE among brain cells, as apoE is the major transport protein for extracellular cholesterol and other lipids, and that apoE-mediated cholesterol exchange occurs between neuronal and nonneuronal cells in CNS (Lahiri, 2004). The stability of apoE in the brain requires the association with lipids. The apoE level is decreased in abca1 knockout mice, which is a gene necessary for the apoE lipidation (Wahrle et al., 2004; Hirsch-Reinshagen et al., 2005).

In vitro cultured astrocytes, apoE knockout showed reduced lipoprotein secretion (Piedrahita et al., 1992; Plump et al., 1992), but it remains controversial in apoE knockout mice. Some studies revealed normal cholesterol contents (Jansen et al., 2000; Lomnitski et al., 1999; Han et al., 2003) and turnover in brain, on the other hand, other studies showed reduced cholesterol level (Levi et al., 2005). Lipoproteins secreted by cultured astrocytes contain cholesterol and phospholipids, but relatively little esterified cholesterol. Some cholesterol precursors like lathosterol and desmosterol were detected in glia-derived lipoproteins, indicating that the precursor form may be converted to cholesterol in neurons after uptake. Epidemiology studies reveal the link between apoE with late-onset Alzheimer's disease. ApoE isoform $\varepsilon 4$ is the most common risk factor identified so far (Corder et al., 1993). $\varepsilon 4$ alleles also correlate with amyloid plaques in Alzheimer patient's autopsy (Schmechel et al., 1993).

\section{ATP-binding cassette (ABC) transporter in CNS- Lipoprotein Lipidation}

ATP-binding cassette $(A B C)$ transporters are essential component for mediating lipid transport in CNS, especially in the formation of apoE-containing lipoproteins (Tachikawa et al., 2005). ABCA and ABCG are the major classes in the brain, they are critical for lipid homeostasis (Dean et al., 2001; Schmitz et al., 2000; Puglielli et al., 2003). The core lipoprotein particle is assemblied in ER, the lipidation of nascent particles is mediated by specific subtypes of the ATP binding cassette $(A B C)$ transporters. Cholesterol metabolite 24-OHC can up-regulate ABCA1's expression, $A B C A 1$, then, can mediate cholesterol efflux in the brain and influence whole-brain cholesterol homeostasis. ABCA1 catalyzes the initial transfer of lipids onto lipid-free apolipoproteins, including apoE, to form nascent particles, which are then fully lipidated in a second phase of efflux mediated by ABCG1 (Gelissen et al., 2006; Vaughan and Oram, 2006). ABCA1 is expressed in both neurons and glial cells, but much higher level in neurons than in glial cells (Wellington et al., 2002; Koldamova et al., 2003; Fukumoto et al., 2002). Neuron and glia specific ABCA1 deficiency leads to poor lipidation of apoE, and significant decrease of cholesterol level, decrease of apoE level in brain and CSF and size of apoE-containing lipoproteins in CSF (Hirsch-Reinshagen et al., 2004), suggesting that poorly lipidated apoE is more rapidly cleared. This may indicate that enhanced catabolism of apoE due to insufficient lipidation. A genetic study on human subjects showed that a single nucleotide polymorphism in the abca1 gene highly correlates with cholesterol level in CSF (Wollmer et al., 2003b). ABCA1 transfers celluar cholesterol to acceptors like APOA1 (Oram and Heinecke, 2005). The cholesterol efflux from cultured astrocytes can be enhanced by agonists of liver $x$ receptors (LXRs) treatment. These nuclear receptors control expression of proteins that mediate cellular cholesterol release including apoE. All the 
evidences indicate that ABCA1 is a crucial molecule for apoE-containing lipoprotein formation in CNS.

\section{LDL receptor family in the CNS}

Numerous lipoprotein receptors of LDL receptor family have been identified in CNS including LDL receptor, VLDL-receptor, apoER2/LRP8, LRP4, LRP, LRP2 (megalin), LRP1B, LRP5/LRP6, and LRP11/SORL1 (Herz, 2009; Pottier et al., 2012). Ligands for these receptors are apoEcontaining lipoproteins, lipids and other macromolecules (Ignatius et al., 1987; Pitas et al., 1987b). Among them, the LDL-receptor and LRP1 are the main receptors for the uptake of apoE-containing lipoprotein particles in the brain. The major difference between LRP1 and LDLR is that the latter is more highly expressed in glial cells than in neurons, but LRP1 is more highly expressed in neurons than in glial cells (Rebeck et al., 1993). LRP1 appears to have the highest transport capacity for apoE, due to its rapid endocytic rates (Li et al., 2001). ApoE associated with lipid may induce a strong anti-apoptotic effect and protect cells against neurodegeneration through an intercellular signaling pathway. LDL-receptor knockout mice have increased levels of apoE in brain parenchyma and in CSF (Liu et al., 2010), conditional deletion of Lrp1 gene in mouse brain significantly decreases apoE, cholesterol, and sulfatide (Liu et al., 2010). ApoE lipoprotein particles secreted by glial cells have higher affinity for LDLR than LRP1, but CSFisolated high-density lipoprotein (HDL) particles bind more strongly to LRP1 (Fagan et al., 1996). The conformation and lipidation status of apoE may affect the specificity of its receptor binding.

NPC1/NPC2-redistribution of lipoprotein-derived cholesterol

Externally uptaken cholesterol enters endosome/lysosome before reaches to subcellular membrane compartments (Soccio and Breslow, 2004; Storch and Xu, 2009). Two components, namely Niemann-Pick type C1 (NPC1) and C2 (NPC2), are highly involved in this process. NPC1 and NPC2 are expressed in both neurons and glial cells (Prasad et al., 2000; Ong et al., 2004; German et al., 2002; Patel et al., 1999; Hu et al., 2000). NPC1 is a transmembrane protein with a sterol-sensitive domain (Carstea et al., 1997) and NPC2 is an intralumenal component that binds cholesterol (Naureckiene et al., 2000; Soccio and Breslow, 2004). The dysfunction of either protein causes accumulation of unesterified cholesterol in the late endosome/lysosome and pathologic changes in neurons and glial cells (Reid et al., 2004; Baudry et al., 2003). Conditional NPC1 knockout in Purkinje cells leads to age-dependent motor deficits and Purkinje cell degeneration (Elrick et al., 2010), rescue of NPC1 in neurons prevented neuronal degeration (Lopez et al., 2011).

\section{CHOLESTEROL AND ALZHEIMER'S DISEASE}

Alzheimer's disease (AD) is a neurodegenerative disorder characterized by progressive and irreversible memory impairment and cognitive decline. The pathological hallmarks of $A D$ are extracellular amyloid plaques of amyloid $\beta(A \beta)$ peptide and intracellular neurofibrillary tangles. Cholesterol is found to be enriched in the brain plasma membranes of AD patients. The cholesterol level increases throughout the course of clinical disease, and more increase was observed when the disease progresses (Cutler et al., 2004; Xiong et al., 2008). In vitro study indicated that overload of cholesterol at plasma membrane in primary cultured neurons leads to an increase of $A \beta$ production through increasing BACE1-mediated APP cleavage (Marquer et al., 2011). APP intracellular domain (AICD) release increases during this process, which down-regulates low density lipoprotein-related protein 1 (LRP1) transcription that is responsible for exogenous cholesterol capture at the plasma membrane (Liu et al., 2007), this ultimately results in a decrease of cellular cholesterol levels.

\section{CHOLESTEROL IN THE BRAIN AND PERIPHERAL SYSTEM}

Cholesterol is an essential structural component for plasma membrane both in brain and peripheral tissue. It is required to build and maintain membrane, modulate membrane fluidity. The brain contains about $20 \%$ of whole body cholesterol, brain cholesterol is deeply involved in synapse development, synapse formation, dentrite differentiation, axonal elongation, and long-term potentiation. On the other hand, peripheral cholesterol is an important precursor molecule for the synthesis of Vitamin $D$ and the steroid hormones. Cholesterol is converted to bile in the liver, bile salts solubilize fats and aid in intestinal absorption. Lowdensity lipoprotein (LDL) particles are the major blood cholesterol carriers. When LDL particles are overloaded in the blood stream, they tend to be oxidized and taken up by macrophages, which become trapped in the walls of blood vessels and contribute to atherosclerotic plaque formation. In contrast, high-density lipoprotein (HDL) particles transport cholesterol back to the liver through reverse cholesterol transport, either for excretion or for synthesis of hormones.

\section{CONCLUSION AND OUTLOOK}

The investigation of cholesterol metabolism in the brain has a long history, but this field has gained momentum only within the last decade, probably because cholesterol is implied in neurodegenerative disease. Cells in the brain manage to keep their cholesterol content at required level in a way that is different from the rest of the body. Neurons and astrocytes, more importantly, their cooperation is essential for brain development and function. Astrocytes and neurons synthesize cholesterol by slightly different pathways and at different rates. Several pathways mediate cholesterol excretion from the brains, cholesterol hydroxylation has been proven to be the 
most efficient way by neurons. There is a cell-specific distribution of proteins that are involved in cholesterol metabolism. For example, apoE is highly expressed only in astrocytes, but not in neurons. This allows cholesterol transport happening between different brain cells. CYP46 is highly expressed in neurons, but not in astrocytes, this enables the removal of surplus cholesterol from the neurons.

However, questions like whether all neurons rely on cholesterol supplied by astrocytes, the regulation of cholesterol transport from astrocytes to neurons, the crosstalk between neuron and astrocyte during this process still remain unclear. The understanding of cholesterol metabolism in the brain and its role in disease requires further studies.

\section{ACKNOWLEDGEMENTS}

This review was supported by grants from the National Natural Science Foundation of China (Grant Nos. 81422015, 91332111, and 31371087), the National Basic Research Program (973 Program) (No. 2014CB548100), the Fundamental Research Funds for the Central Universities, NN-CAS Research foundation, and the Thousand Young Talents Program (Q. Liu).

\section{ABBREVIATIONS}

7D, 7-dehydro-cholesterol; 24-OHC, 24-hydroxycholesterol; ABCA1, ATP-binding cassette transporter A1; AD, Alzheimer's disease; AICD, APP intracellular domain; ApoE, apolipoprotein E; APP, Alzheimer precursor protein; BACE1, beta-secretase 1; CYP46, cytochrome P450 cholesterol 24-hydroxylase; $\mathrm{CH}$, cholesterol; DE, desmosterol; DHCR7, 7-dehydrocholesterol reductase; DHCR24, 24-dehydrocholesterol reductase; HMG-CoA, 3-hydroxy-3methylglutaryl-CoA; HMGCR, 3-hydroxy-3-methyl-glutaryl-CoA reductase; LA, lanosterol; LDLR, low density lipoprotein receptor; LRP1, low density lipoprotein receptor-related protein 1; LT, lathosterol; LXRs, liver $x$ receptors; NPC1, Niemann-Pick type C protein 1; NPC2, Niemann-Pick type C protein 2; PD, Parkinson's disease; ZN, zymostenol; ZY, zymosterol.

\section{COMPLIANCE WITH ETHICS GUIDELINES}

Juan Zhang and Qiang Liu declare that they have no conflict of interest.

This article does not contain any studies with human or animal subjects performed by the any of the authors.

\section{OPEN ACCESS}

This article is distributed under the terms of the Creative Commons Attribution License which permits any use, distribution, and reproduction in any medium, provided the original author(s) and the source are credited.

\section{REFERENCES}

Andersson M, Elmberger PG, Edlund C, Kristensson K, Dallner G (1990) Rates of cholesterol, ubiquinone, dolichol and dolichyl-P biosynthesis in rat brain slices. FEBS Lett 269:15-18
Baudry M, Yao Y, Simmons D, Liu J, Bi X (2003) Postnatal development of inflammation in a murine model of Niemann-Pick type $C$ disease: immunohistochemical observations of microglia and astroglia. Exp Neurol 184:887-903

Berg JM (2002) The complex regulation of cholesterol biosynthesis takes place at several levels. Biochemistry, 5th edn. W.H. Freeman, New York

Björkhem I (2006) Crossing the barrier: oxysterols as cholesterol transporters and metabolic modulators in the brain. J Intern Med 260:493-508

Björkhem I, Meaney S, Fogelman AM (2004) Brain cholesterol: long secret life behind a barrier. Arterioscler Thromb Vasc Biol 24:806815

Björkhem I, Heverin M, Leoni V, Meaney S, Dicz-falusy U (2006) Oxysterols and Alzheimer's disease. Acta Neurol Scand 114:43-49

Block RC, Dorsey ER, Beck CA, Brenna JT, Shoulson I (2010) Altered cholesterol and fatty acid metabolism in Huntington disease. J Clin Lipidol 4:17-23

Boyles JK, Notterpek LM, Anderson LJ (1990) Accumulation of apolipoproteins in the regenerating and remyelinating mammalian peripheral nerve. Identification of apolipoprotein $D$, apolipoprotein A-IV, apolipoprotein E, and apolipoprotein A-I. J Biol Chem 265:17805-17815

Brown MS, Goldstein JL (1999) A proteolytic pathway that controls the cholesterol content of membranes, cells, and blood. Proc Natl Acad Sci 96:11041-11048

Bryleva EY, Rogers MA, Chang CC, Buen F, Harris BT, Rousselet E et al (2010) ACAT1 gene ablation increases 24(S)-hydroxycholesterol content in the brain and ameliorates amyloid pathology in mice with AD. Proc Natl Acad Sci 107:3081-3086

Cahoy JD et al (2008) A transcriptome database for astrocytes, neurons, and oligodendrocytes: a new resource for understanding brain development and function. J Neurosci 28:264-278

Carstea ED, Morris JA, Coleman KG, Loftus SK, Zhang D, Cummings $C$ et al (1997) Niemann-Pick C1 disease gene: homology to mediators of cholesterol homeostasis. Science 277:228-231

Christopherson KS et al (2005) Thrombospondins are astrocytesecreted proteins that promote CNS synaptogenesis. Cell 120:421-433

Corder EH, Saunders AM, Strittmatter WJ et al (1993) Gene dose of apolipoprotein $\mathrm{E}$ type 4 allele and the risk of Alzheimer's disease in late onset families. Science 261:921-923

Cutler RG, Kelly J, Storie K, Pedersen WA, Tammara A, Hatanpaa K, Troncoso JC, Mattson MP (2004) Involvement of oxidative stress-induced abnormalities in ceramide and cholesterol metabolism in brain aging and Alzheimer's disease. Proc Natl Acad Sci USA 101:2070-2075

De Chaves El, Rusinol AE, Vance DE, Campenot RB, Vance JE (1997) Role of lipoproteins in the delivery of lipids to axons during axonal regeneration. J Biol Chem 272:30766-30773

Dean M, Hamon Y, Chimini G (2001) The human ATP-binding cassette (ABC) transporter superfamily. J Lipid Res 42:1007-1017

DeBose-Boyd RA, Brown MS, Li WP, Nohturfft A, Goldstein JL, Espenshade PJ (1999) Transport-dependent proteolysis of SREBP: relocation of Site-1 protease from Golgi to ER obviates the need for SREBP transport to Golgi. Cell 99:703-712 
DeGrella RF, Simoni RD (1982) Intracellular transport of cholesterol to the plasma membrane. J Biol Chem 257:14256-14262

Di Paolo G, Kim TW (2011) Linking lipids to Alzheimer's disease: cholesterol and beyond. Nat Rev Neurosci 12:284-296

Dietschy JM, Turley SD (2004) Cholesterol metabolism in the central nervous system during early development and in the mature animal. J Lipid Res 45:1375-1397

Elrick MJ, Pacheco CD, Yu T, Dadgar N, Shakkottai VG, Ware C et al (2010) Conditional Niemann-Pick $C$ mice demonstrate cell autonomous Purkinje cell neurodegeneration. Hum Mol Genet 19:837-847

Fagan AM, Holtzman DM (2000) Astrocyte lipoproteins, effects of apoE on neuronal function, and role of apoE in amyloid-beta deposition in vivo. Microsc Res Tech 50:297-304

Fagan AM, Bu G, Sun Y, Daugherty A, Holtzman DM (1996) Apolipoprotein E-containing high density lipoprotein promotes neurite outgrowth and is a ligand for the low density lipoprotein receptor-related protein. J Biol Chem 271:30121-30125

Fester L, Zhou L, Bütow A (2009) Cholesterol-promoted synaptogenesis requires the conversion of cholesterol to estradiol in the hippocampus. Hippocampus 19:692-705

Fox MA, Umemori H (2006) Seeking long-term relationship: axon and target communicate to organize synaptic differentiation. $J$ Neurochem 97:1215-1231

Fukumoto H, Deng A, Irizarry MC, Fitzgerald ML, Rebeck GW (2002) Induction of the cholesterol transporter ABCA1 in central nervous system cells by liver $x$ receptor agonists increases secreted abeta levels. J Biol Chem 277:48508-48513

Fünfschilling U, Saher G, Xiao L, Möbius W, Nave KA (2007) Survival of adult neurons lacking cholesterol synthesis in vivo. BMC Neurosci 2:1-8

Gelissen IC, Harris M, Rye KA, Quinn C, Brown AJ, Kockx M et al (2006) ABCA1 and ABCG1 synergize to mediate cholesterol export to apoA-I. Arterioscler Thromb Vasc Biol 26:534-540

German DC, Liang CL, Song T, Yazdani U, Xie C, Dietschy JM (2002) Neurodegeneration in the Niemann-Pick C mouse: glial involvement. Neuroscience 109:437-450

Goritz C, Mauch DH, Pfrieger FW (2005) Multiple mechanisms mediate cholesterol-induced synaptogenesis in a CNS neuron. Mol Cell Neurosci 29:190-201

Gosselet F, Candela P, Sevin E, Berezowski V, Cecchelli R, Fenart L (2009) Transcriptional profiles of receptors and transporters involved in brain cholesterol homeostasis at the blood-brain barrier: use of an in vitro model. Brain Res 1249:34-42

Han X, Cheng H, Fryer JD, Fagan AM, Holtzman DM (2003) Novel role for apolipoprotein $E$ in the central nervous system. Modulation of sulfatide content. J Biol Chem 278:8043-8051

Heino S, Lusa S, Somerharju P, Ehnholm C, Olkkonen VM, Ikonen E (2000) Dissecting the role of the Golgi complex and lipid rafts in biosynthetic transport of cholesterol to the cell surface. Proc Natl Acad Sci 97:8375-8380

Herz J (2009) Apolipoprotein E receptors in the nervous system". Curr Opin Lipidol 20:190-196

Hirsch-Reinshagen V, Zhou S, Burgess BL, Bernier L, Mclsaac SA, Chan JY et al (2004) Deficiency of ABCA1 impairs apolipoprotein E metabolism in brain. J Biol Chem 279:41197-41207
Hirsch-Reinshagen V, Maia LF, Burgess BL et al (2005) The absence of ABCA1 decreases soluble ApoE levels but does not diminish amyloid deposition in two murine models of Alzheimer disease. J Biol Chem 280:43243-43256

Hu CY, Ong WY, Patel SC (2000) Regional distribution of NPC1 protein in monkey brain. J Neurocytol 29:765-773

Hutter-Paier B, Huttunen HJ, Puglielli L, Eckman CB, Kim DY, Hofmeister A et al (2004) The ACAT inhibitor CP-113, 818 markedly reduces amyloid pathology in a mouse model of Alzheimer's disease. Neuron 44:227-238

Ignatius MJ, Gebicke-Harter PJ, Skene JH, Schilling JW, Weisgrabber KH, Mahley RW, Shooter EM (1986) Expression of apolipoprotein $\mathrm{E}$ during nerve degeneration and regeneration. Proc Natl Acad Sci USA 83:1125-1129

Ignatius MJ, Shooter EM, Pitas RE, Mahley RW (1987) Lipoprotein uptake by neuronal growth cones in vitro. Science 236:950-962

Ikonen E (2008) Cellular cholesterol trafficking and compartmentalization. Nat Rev Mol Cell Biol 9:125-138

Janowski BA, Grogan MJ, Jones SA, Wisely GB, Kliewer SA, Corey EJ, Mangelsdorf DJ (1999) Structural requirements of ligands for the oxysterol liver X receptors LXRalpha and LXRbeta. Proc Natl Acad Sci 96:266-271

Jansen PJ, Lutjohann D, Thelen KM, von Bergmann $K$, van Leuven F, Ramaekers FC et al (2000) Absence of ApoE upregulates murine brain ApoD and ABCA1 levels, but does not affect brain sterol levels, while human ApoE3 and human ApoE4 upregulate brain cholesterol precursor levels. J Alzheimers Dis 18:319-329

Jeske DJ, Dietschy JM (1980) Regulation of rates of cholesterol synthesis in vivo in the liver and carcass of the rat measured using $[3 \mathrm{H}]$ water. J. Lipid Res 21:364-376

Jurevics $H$, Morell $P$ (1995) Cholesterol for synthesis of myelin is made locally, not imported into brain. J Neurochem 64:895-901

Jurevics HA, Kidwai FZ, Morell P (1997) Sources of cholesterol during development of the rat fetus and fetal organs. J Lipid Res 38:723-733

Kaplan MR, Simoni RD (1985) Transport of cholesterol from the endoplasmic reticulum to the plasma membrane. J Cell Biol 101:446-453

Karten B, Campenot RB, Vance DE, Vance JE (2006) Expression of $A B C G 1$, but not $A B C A 1$, correlates with cholesterol release by cerebellar astroglia. J Biol Chem 281:4049-4057

Kim WS, Weickert CS, Garner B (2008) Role of ATP-binding cassette transporters in brain lipid transport and neurological disease. J Neurochem 104:1145-1166

Ko M, Zou K, Minagawa $\mathrm{H}$ et al (2005) Cholesterol-mediated neurite outgrowth is differently regulated between cortical and hippocampal neurons. J Biol Chem 52:42759-42765

Koch S, Donarski N, Goetze K, Kreckel M, Stuerenburg $\mathrm{HJ}$, Buhmann C et al (2001) Characterization of four lipoprotein classes in human cerebrospinal fluid. J Lipid Res 42:1143-1151

Koldamova RP, Lefterov IM, Ikonomovic MD, Skoko J, Lefterov PI, Isanski BA et al (2003) 22R-hydroxycholesterol and 9-cis-retinoic acid induce ATP-binding cassette transporter A1 expression and cholesterol efflux in brain cells and decrease amyloid beta secretion. J Biol Chem 278:13244-13256 
Korade Z, Kenworthy AK (2008) Lipid rafts, cholesterol, and the brain. Neuropharmacology 55:1265-1273

Lahiri DK (2004) ApolipoproteinEasatargetfordevelopingnew therapeutics for Alzheimer's disease based on studies from protein, the gene. J Mol Neurosci 23:225-233

Lange Y, Ye J, Strebel F (1995) Movement of 25-hydroxycholesterol from the plasma membrane to the rough endoplasmic reticulum in cul- tured hepatoma cells. J Lipid Res 36:1092-1097

Levi O, Lutjohann D, Devir A, von Bergmann K, Hartmann T, Michaelson DM (2005) Regulation of hippocampal cholesterol metabolism by apoE and environmental stimulation. J Neurochem 95:987-997

Li Y, Lu W, Marzolo MP, Bu G (2001) Differential functions of members of the low density lipoprotein receptor family suggested by their distinct endocytosis rates. J Biol Chem 276:18000-18006

Liang Y, Lin S, Beyer TP, Zhang Y, Wu X, Bales KR, DeMattos RB, May PC, Li SD, Jiang XC Eacho PI, Cao G, Paul SM (2004) A liver $X$ receptor and retinoid $X$ receptor heterodimer mediates apolipoprotein $\mathrm{E}$ expression secretion and cholesterol homeostasis in astrocyte. J NeuroChem 88:623-634

Linetti A, Fratangeli A, Taverna E, Valnegri P, Francolini M, Cappello $\checkmark$ et al (2010) Cholesterol reduction impairs exocytosis of synaptic vesicles. J Cell Sci 123:595-605

Linton MF, Gish R, Hubl ST et al (1991) Phenotypes of apolipoprotein $\mathrm{B}$ and apolipoprotein $\mathrm{E}$ after liver transplantation. J Clin Investig 88:270-281

Liu Q, Zerbinatti CV, Zhang J, Hoe HS, Wang B, Cole SL et al (2007) Amyloid precursor protein regulates brain apolipoprotein $\mathrm{E}$ and cholesterol metabolism through lipoprotein receptor LRP1. Neuron 56:66-78

Liu B, Turley SD, Burns DK, Miller AM, Repa JJ, Dietschy JM (2009) Reversal of defective lysosomal transport in NPC disease ameliorates liver dysfunction and neurodegeneration in the npc1-/- mouse. Proc Natl Acad Sci 106:2377-2382

Liu Q, Trotter J, Zhang J, Peters MM, Cheng H, Bao J et al (2010) Neuronal LRP1 knockout in adult mice leads to impaired brain lipid metabolism and progressive, age-dependent synapse loss and neurodegeneration. J Neurosci 30:17068-17078

Lomnitski L, Oron L, Sklan D, Michaelson DM (1999) Distinct alterations in phospholipid metabolism in brains of apolipoprotein E-deficient mice. J Neurosci Res 58:586-592

Lopez ME, Klein AD, Dimbil UJ, Scott MP (2011) Anatomically defined neuron-based rescue of neurodegenerative NiemannPick type C disorder. J Neurosci 31:4367-4378

Lund EG, Guileyardo JM, Russell DW (1999) cDNA cloning of cholesterol 24-hydroxylase, a mediator of cholesterol homeostasis in the brain. Proc Natl Acad Sci USA 96(13):7238-7243

Lund EG, Xie C, Kotti T, Turley SD, Dietschy JM, Russell DW (2003) Knockout of the cholesterol 24-hydroxylase gene in mice reveals a brain-specific mechanism of cholesterol turnover. J Biol Chem 25:22980-22988

Lütjohann D, Breuer O, Ahlborg G, Nennesmo I, Sidén A, Diczfalusy U, Björkhem I (1996) Cholesterol homeostasis in human brain: evidence for an age-dependent flux of 24S-hydroxycholesterol from the brain into the circulation. Proc Natl Acad Sci USA 93:9799-9804
Madra M, Sturley SL (2010) Niemann-Pick type C pathogenesis and treatment: from statins to sugars. Clin Lipidol 5:387-395

Mahley RW, Weisgraber KH, Huang Y (2006) Apolipopro- tein E4: a causative factor and therapeutic target in neuropathology, including Alzheimer's disease. Proc Natl Acad Sci USA 103:5644-5651

Marquer C, Devauges V, Cossec JC, Liot G, Lecart S, Saudou F, Duyckaerts C, Leveque-Fort S, Potier MC (2011) Local cholesterol increase triggers amyloid precursor protein-BACE1 clustering in lipid rafts and rapid endocytosis. FASEB J 25:1295-1305

Matsuda A, Nagao K, Matsuo M, Kioka N, Ueda K (2013) 24(S)hydroxycholesterol is actively eliminated from neuronal cells by ABCA1. J Neurochem 126:93-101

Mauch DH et al (2001) CNS synaptogenesis promoted by gliaderived cholesterol. Science 294:1354-1357

Meaney S, Bodin K, Diczfalusy U, Bjorkhem I (2002) On the rate of translocation in vitro and kinetics in vivo of the major oxysterols in human circulation: critical importance of the position of the oxygen function. J Lipid Res 43:2130-2135

Minagawa H, Gong JS, Jung CG, Watanabe A, Lund-Katz S, Phillips $\mathrm{MC}$ et al (2009) Mechanism underlying apolipoprotein $\mathrm{E}$ (ApoE) isoform-dependent lipid efflux from neural cells in culture. J Neurosci Res 87:2498-2508

Morell P, Jurevics H (1996) Origin of cholesterol in myelin. Neurochemical Research 21:463-470

Naureckiene S, Sleat D, Lackland H, Fensom A, Vanier MT, Wattiaux R et al (2000) Identification of HE1 as the second gene of Niemann-Pick C disease. Science 290:2298-2301

Nieweg K, Schaller H, Pfrieger FW (2009) Marked differences in cholesterol synthesis between neurons and glial cells from postnatal rats. J Neurochem 109:125-134

Nohturfft A, Yabe D, Goldstein JL, Brown MS, Espenshade PJ (2000) Regulated step in cholesterol feedback localized to budding of SCAP from ER membranes. Cell 102:315-323

Numakawa T, Suzuki S, Kumamaru E, Adachi N, Richards M, Kunugi $H$ (2010) BDNF function and intracellular signaling in neurons. Histol Histopathol 25:237-258

Ollila S, Hyvö nen MT, Vattulainen I (2007) Polyunsatu- ration in lipid membranes: dynamic properties and lateral pressure profiles. J Phys Chem B 111:3139-3150

Ong WY, Sundaram RK, Huang E, Ghoshal S, Kumar U, Pentchev PG et al (2004) Neuronal localization and association of Niemann Pick C2 protein (HE1/ NPC2) with the postsynaptic density. Neuroscience 128:561-570

Oram JF, Heinecke JW (2005) ATP-binding cassette transporter A1: a cell cholesterol exporter that protects against cardiovascular disease. Physiol Rev 85:1343-1372

Panzenboeck U, Balazs Z, Sovic A, Hrzenjak A, Levak-Frank S, Wintersperger $A$ et al (2002) ABCA1 and scavenger receptor class B, type I, are modulators of reverse sterol transport at an in vitro blood-brain barrier constituted of porcine brain capillary endothelial cells. J Biol Chem 277:42781-42789

Patel SC, Suresh S, Kumar U, Hu CY, Cooney A, Blanchette-Mackie EJ et al (1999) Localization of Niemann-Pick C1 protein in astrocytes: implications for neuronal degeneration in NiemannPick type C disease. Proc Natl Acad Sci USA 96:1657-1662 
Pfenninger KH (2009) Plasma membrane expansion: a neuron's Herculean task. Nat Rev Neurosci 10:251-261

Pfrieger FW, Barres BA (1997) Synaptic efficacy enhanced by glial cells in vitro. Science 277:1684-1687

Pfrieger FW, Ungerer N (2011) Cholesterol metabolism in neurons and astrocytes. Prog Lipid Res 50:357-371

Piedrahita JA, Zhang SH, Hagaman JR, Oliver PM, Maeda N (1992) Generation of mice carrying a mutant apolipoprotein $\mathrm{E}$ gene inactivated by gene targeting in embryonic stem cells. Proc Natl Acad Sci USA 89:4471-4475

Pitas RE, Boyles JK, Lee SH, Hui D, Weisgraber KH (1987a) Lipoproteins and their receptors in the central nervous system. Characterization of the lipoproteins in cerebrospinal fluid and identification of apolipoprotein $B, E(L D L)$ receptors in the brain. J Biol Chem 262:14352-14360

Pitas RE, Boyles JK, Lee SH (1987b) Astrocytes synthesize apolipoprotein $\mathrm{E}$ and metabolize apolipoprotein E- containing lipoproteins. Biochimi et Biophys Acta 917:148-161

Plump AS, Smith JD, Hayek T, Aalto-Setala K, Walsh A, Verstuyft JG et al (1992) Severe hypercholesterolemia and atherosclerosis in apolipoprotein E- deficient mice created by homologous recombination in ES cells. Cell 71:343-353

Pooler AM, Xi SC, Wurtman RJ (2006) The 3- hydroxy-3-methylglutaryl co-enzyme A reductase inhibitor pravastatin enhances neurite outgrowth in hippocampal neurons. J Neurochem 97:716-723

Pottier C, Hannequin D, Coutant S et al (2012) High frequency of potentially pathogenic SORL1 mutations in autosomal dominant early-onset Alzheimer disease. Mol Psychiarty 17:875-879

Prasad A, Fischer WA, Maue RA, Henderson LP (2000) Regional and developmental expression of the Npc1 mRNA in the mouse brain. J Neurochem 75:1250-1257

Puglielli L, Tanzi RE, Kovacs DM (2003) Alzheimer's disease: the cholesterol connection. Nat Neurosci 6:345-351

Quan G, Xie C, Dietschy JM, Turley SD (2003) Ontogenesis and regulation of cholesterol metabolism in the central nervous system of the mouse. Brain Res Dev Brain Res 146:87-98

Radhakrishnan A, Ikeda Y, Kwon HJ, Brown MS, Goldstein JL (2007) Sterol-regulated transport of SREBPs from endoplasmic reticulum to Golgi: oxysterols block transport by binding to Insig. Proc Natl Acad Sci 104:6511-6518

Ramirez DM, Andersson S, Russell DW (2008) Neuronal expression and subcellular localization of cholesterol 24-hydroxylase in the mouse brain. J Comp Neurol 507:1676-1693

Rebeck GW (2004) Cholesterol efflux as a critical component of Alzheimer's disease pathogenesis. J Mol Neurosci 23:219-224

Rebeck GW, Reiter JS, Strickland DK, Hyman BT (1993) Apolipoprotein E in sporadic Alzheimer's disease: allelic variation and receptor interactions. Neuron 11:575-580

Reid PC, Sakashita N, Sugii S, Ohno-Iwashita Y, Shimada Y, Hickey WF et al (2004) A novel cholesterol stain reveals early neuronal cholesterol accumulation in the Niemann-Pick type C1 mouse brain. J Lipid Res 45:582-591

Roheim PS, Carey M, Forte T, Vega GL (1979) Apolipoproteins in human cerebrospinal fluid. Proc Natl Acad Sci USA 76:646-649

Saher G, Brügger B, Lappe-Siefke C et al (2005) High cholesterol level is essential for myelin membrane growth. Nature Neuroscience 8:468-475
Saito K, Dubreuil V, Arai Y, Wilsch-Brauninger M, Schwudke D, Saher $\mathrm{G}$ et al (2009) Ablation of cholesterol biosynthesis in neural stem cells increases their VEGF expression and angiogenesis but causes neuron apoptosis. Proc Natl Acad Sci 106:8350-8355

Sakashita N, Miyazaki A, Takeya M, Horiuchi S, Chang CC, Chang TY et al (2000) Localization of human acyl-coenzyme A: cholesterol acyltransferase-1 (ACAT-1) in macrophages and in various tissues. Am J Pathol 156:227-236

Schmechel DE, Saunders AM, Strittmatter WJ et al (1993) Increased amyloid $\beta$-peptide deposition in cerebral cortex as a consequence of apolipoprotein $\mathrm{E}$ genotype in late-onset Alzheimer disease. Proc Natl Acad Sci 90:9649-9653

Schmitz G, Kaminski WE, Orso E (2000) ABC transporters in cellular lipid trafficking. Curr Opin Lipidol 11:493-501

Snipes GJ, McGuire CB, Norden JJ, Freeman JA (1986) Nerve injury stimulates the secretion of apolipoprotein $\mathrm{E}$ by nonneuronal cells. Proc Natl Acad Sci USA 83:1130-1134

Soccio RE, Breslow JL (2004) Intracellular cholesterol transport. Arterioscler Thromb Vasc Biol 24:1150-1160

Storch J, Xu Z (2009) Niemann-Pick C2 (NPC2) and intracellular cholesterol trafficking. Biochim Biophys Acta 1791:671-678

Tachikawa M, Watanabe M, Hori S, Fukaya M, Ohtsuki S, Asashima T, Terasaki T (2005) Distinct spatio-temporal expression of ABCA and $A B C G$ transporters in the developing and adult mouse brain. J Neurochem 95:294-304

Takamori S, Holt M, Stenius K, Lemke EA, Gronborg M, Riedel D et al (2006) Molecular anatomy of a trafficking organelle. Cell 127:831-846

Tall AR (2008) Cholesterol efflux pathways and other potential mechanisms involved in the athero-protective effect of high density lipoproteins. J Intern Med 263:256-273

Tarr PT, Edwards PA (2008) ABCG1 and ABCG4 are coexpressed in neurons and astrocytes of the CNS and regulate cholesterol homeostasis through SREBP-2. J Lipid Res 49:169-182

Thelen KM, Falkai P, Bayer TA, Lütjohann D (2006) Cholesterol synthesis rate in human hippocampus declines with aging. Neurosci Lett 403:15-19

Ullian EM, Sapperstein SK, Christopherson KS, Barres BA (2001) Control of synapse number by glia. Science 291:657-661

Valdez CM, Smith MA, Perry G, Phelix CF, Santamaria F (2010) Cholesterol homeostasis markers are localized to mouse hippocampal pyramidal and granule layers. Hippocampus 20:902-905

Vance JE, Pan D, Campenot RB, Bussiere M, Vance DE (1994) Evidence that the major membrane lipids, except cholesterol, are made in axons of cultured rat sympathetic neurons. J Neurochem 62:329-337

Vaughan AM, Oram JF (2006) ABCA1 and ABCG1 or ABCG4 act sequentially to remove cellular cholesterol and generate cholesterol-rich HDL. J Lipid Res 47:2433-2443

Wahrle SE, Jiang H, Parsadanian M et al (2004) ABCA1 is required for normal central nervous system apoE levels and for lipidation of astrocyte-secreted apoE. J Biol Chem 279:40987-40993

Wang Q, Yan J, Chen X, Li J, Yang Y, Weng J et al (2011) Statins: multiple neuroprotective mechanisms in neurodegenerative diseases. Exp Neurol 230:27-34

Wellington CL, Walker EK, Suarez A, Kwok A, Bissada N, Singaraja $R$ et al (2002) ABCA1 mRNA and protein distribution patterns 
predict multiple different roles and levels of regulation. Lab Invest 82:273-283

Wollmer MA, Streffer JR, Tsolaki M, Grimaldi LM, Lutjohann D, Thal $D$ et al (2003a) Genetic association of acyl-coenzyme A: cholesterol acyltransferase with cerebrospinal fluid cholesterol levels, brain amyloid load, and risk for Alzheimer's disease. Mol Psychiatry 8:635-638

Wollmer MA, Streffer JR, Lutjohann D, Tsolaki M, lakovidou V, Hegi $T$ et al (2003b) ABCA1 modulates CSF cholesterol levels and influences the age at onset of Alzheimer's disease. Neurobiol Aging 24:421-426

Wustner D, Mondal M, Tabas I, Maxfield FR (2005) Direct observation of rapid internalization and intracellular transport of sterol by macrophage foam cells. Traffic 6:396-412

Xiong $\mathrm{H}$, Callaghan D, Jones A, Walker DG, Lue LF, Beach TG, Sue LI, Woulfe J, Xu H, Stanimirovic DB et al (2008) Cholesterol retention in Alzheimer's brain is responsible for high beta- and gamma-secretase activities and A-beta production. Neurobiol Dis 29:422-437

Xu PT, Gilbert JR, Qiu HL, Ervin J, Rothrock-Christian TR, Hulette C, Schmechel DE (1999) Specificregional transcription of apolipoprotein $E$ in human brain neurons. Am J Pathol 154:601-611

Xu X, Bittman R, Duportail G, Heissler D, Vilcheze C, London E (2001) Effect of the structure of natural sterols and sphingolipids on the formation of ordered sphingolipid/ sterol domains (rafts). Comparison of cholesterol to plant, fungal, and disease-associated sterols and comparison of sphingomyelin, cerebrosides, and ceramide. J Biol Chem 276:33540-33546 